\title{
37. COMMISSION DES AMAS STELLAIRES
}

PRÉsident: O. Heckmann, Hamburger Sternwarte, Hamburg-Bergedorf, Germany. Membres: MM. Baade, Barkhatova, W. Becker, Binnendijk, Bok, Chandrasekhar, Cuffey, Eggen, S. Günther, Hertzsprung, Mme Sawyer Hogg, MM. H. L. Johnson, Kholopov, Lohmann, Markarian, N. U. Mayall, Mineur $\dagger$, Rosino, Sandage, H. Shapley, Trumpler†, Vanderlinden, van Wijk, Wallenquist, Weaver.

\section{INTRODUCTION}

The following report consists of four parts: The first part is devoted to associations. According to a proposal of A. Blaauw, approved by the Executive Committee, this subject is now assigned to Commission 37. This arrangement not having been made until recently, only a fraction of the work done in this field can be reflected in this report. The second part is devoted to galactic clusters, and the third one to globular clusters. Each part gives tabular surveys of objects under observation, literature, and a list of instruments used. Tables 2 and 3 are followed by a short discussion of their contents and by special as well as general remarks on items not touched upon before.

These three sections are based on the answers to two circular letters each of which was accompanied by a questionnaire. The first was distributed by W. Becker and J. S. Hall in December I952. It was sent to several members of Commission 37 and some other astronomers. The answers were collected by W. Baade and sent to O. Heckmann in December I953. No answers arrived from the U.S.S.R. The material was examined at Bergedorf by $\mathrm{H}$. Haffner. In July I954 the results, together with a second and enlarged questionnaire, were communicated to all members of Commission 37 and, in addition, to all other astronomers who had received the first letter. Each addressee received two copies, the second one was to be given to any recognized station where cluster investigations were known to be carried out. The contents of the answers are condensed in the following tables. No other information was used, consequently the tables give a survey of cluster work only in so far as it was notified to the President. They cover the time since the Rome meeting till October I954.

The fourth part reports on cluster work in the U.S.S.R. It was prepared by $P . N$. Kholopov, who had not used the questionnaire of the second circular letter. Its form could not well be worked into the tables of the foregoing parts. Therefore Kholopov's report is reproduced here with only slight condensations of the text.

\section{Associations}

Table I. Associations

\begin{tabular}{|c|c|c|c|c|c|}
\hline Name & $\begin{array}{l}\text { Morgan } \\
\text { number }^{a}\end{array}$ & Observer & $\begin{array}{c}\text { Data } \\
\text { observed }^{b}\end{array}$ & $\begin{array}{l}\text { Instru- } \\
\text { mentc }^{c}\end{array}$ & Reference \\
\hline \multirow[t]{5}{*}{ II Per } & 23 & W. Becker & pe mag. UBV & (a) & Z. Ap. 34, I, I954 \\
\hline & & Harris & pe mag. UBV & $(b)$ & - \\
\hline & & Blaauw & r.v. & $(b)$ & - \\
\hline & & Bertiau, Blaauw & s.t. & $(c)$ & - \\
\hline & & Delhaye, Blaauw & p.m. & $(d)$ & B.A.N. I4, 448, I953 \\
\hline \multirow[t]{4}{*}{ I Lac } & 14 & Harris & pe pag. UBV & (b) & - \\
\hline & & Blaauw & r.v. & $(b)$ & - \\
\hline & & Blaauw, W. W. Morgan & p.m. & $(h)$ & $A p . J .117,256,1953$ \\
\hline & & Delhaye & p.m. & (d) & - \\
\hline \multirow[t]{3}{*}{ III Cep } & 17 & Blaauw & p.m. & $(e)$ & - \\
\hline & & Münch & faint members & $(f)$ & - \\
\hline & & Sawyer Hogg & r.v. & $(g)$ & - \\
\hline Sco-Cen & - & Bertiau, Blaauw & p.m. & $(h)$ & 一 \\
\hline \multirow[t]{3}{*}{ UMa } & 一 & Harris & pe mag. UBV & (b) & - \\
\hline & & Miczaika & pe mag. BV & (i) & - \\
\hline & & & $54 I$ & & \\
\hline
\end{tabular}




\section{Notes and References to Table I}

a The Morgan number is taken from W. W. Morgan et al., Ap. J. I18, 318, 1953.

$b$ r.v. = radial velocities; s.t. $=$ spectral types; p.m. $=$ proper motions.

c Instruments used are: (a) 24 in. refl., Bergedorf; (b) 82 in. refl., McDonald; (c) 40 in. refr., Yerkes; (d) 7"6 merid. circle, Paris; $(e)$ Ross 2 m.-astrograph, Yale; $(f) 24$ in. Schmidt, Tonantzintla; $(g) 74$ in. refl., David Dunlap; $(h)$ different meridian circles; $(i) 12$ in. refr. Heidelberg.

Mrs Sawyer Hogg announces that the David Dunlop Observatory is observing radial velocities of stars brighter than 10.6 in the following aggregates listed by Morgan and collaborators (r): 9, I0, II, I2, I3, I6, I7, I8, I9, 20, 21, 24, 27, II Cam.

Weaver reports that a Berkeley group is particularly interested in the motion of associations as regards Ursa Major and Perseus.

\section{Galactic Clusters}

Table 2a. Galactic Clusters

\begin{tabular}{|c|c|c|}
\hline \multirow{3}{*}{$\begin{array}{c}\text { NGC } \\
\mathbf{4 5 7}\end{array}$} & Type & Observer \\
\hline & lb & W. Becker \\
\hline & & $\begin{array}{l}\text { Hoag } \\
\text { Walker }\end{array}$ \\
\hline 559 & & Miller, Becker \\
\hline \multirow[t]{3}{*}{581} & $1-2 b$ & Miller, Becker \\
\hline & & Hoag \\
\hline & & Wallenquist \\
\hline \multirow{4}{*}{$\left.\begin{array}{c}\text { An. Tr. } 1 \\
609 \\
637 \\
654 \\
659\end{array}\right\}$} & & Miller, Becker \\
\hline & & Miller, Becker \\
\hline & & Larsson-Leander \\
\hline & & Larsson-Leander \\
\hline \multirow[t]{2}{*}{663} & $1 \mathrm{~b}$ & W. Becker \\
\hline & & Hoag \\
\hline \multirow[t]{4}{*}{752} & $2 f$ & Eggen \\
\hline & & $\begin{array}{l}\text { Haffner } \\
\text { H. Iohnson }\end{array}$ \\
\hline & & Wallenquist \\
\hline & & $\begin{array}{l}\text { Westerlund } \\
\text { Roman }\end{array}$ \\
\hline \multirow[t]{2}{*}{869} & Ib & H. Johnson \\
\hline & & Dieckvoss, Kox \\
\hline 884 & $1-2 b$ & $\begin{array}{l}\text { H. Johnson } \\
\text { Dieckvoss, Kox }\end{array}$ \\
\hline 957 & & Larsson-Leander \\
\hline \multirow[t]{2}{*}{1039} & $1 \mathrm{~b}-\mathrm{a}$ & H. Johnson \\
\hline & & Wallenquist \\
\hline \multirow[t]{5}{*}{$\alpha \operatorname{Per}$} & $1-2 b$ & $\begin{array}{l}\text { Dieckvoss, Kox } \\
\text { Bahner }\end{array}$ \\
\hline & & Harris \\
\hline & & Heckmann \\
\hline & & Pels \\
\hline & & Ponsen \\
\hline \multirow[t]{2}{*}{ IC 348} & & $\begin{array}{l}\text { Harris, Morgan, } \\
\text { Roman }\end{array}$ \\
\hline & $1 \mathrm{~b}$ & $\begin{array}{l}\text { Walker } \\
\text { Harris }\end{array}$ \\
\hline Pleiades & & H. Johnson \\
\hline
\end{tabular}

$$
\bar{\lambda}
$$

370470640

435530

370435550

370470640

370470640

435530

419536

370470640

370470640

425530650

425530

370470640

435530

430540

370427470640

370435550

419536

435550625

\section{0}

370435550

$$
7
$$
425530650 425530

370435550

419536

430550

370436553

370420470640

3 colours

370435550

370435550

370436553

370435550
Limiting magnitude Method

$14 \cdot 5$

14

$14 \cdot 3$

13

13

14

$11 \cdot 5$

13

pg
pe
pe
pg
pg
pe
pe
pg

Data observed and reference ${ }^{\mathrm{a}}$

Z. Ap. 34, I, 1954 (with Stock)

pe + pg pol. Astr. J. 58, 42, 1953 s.t.

-

pe + pg pol. Astr. J. 58, 42, 1953

13

17

15

14.5

14

15

15

15

11.5

11.5

$12 \cdot 6$

15

15

17

15

15

11.5

13

$10 \cdot 7$

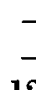

12

10.5

$13 \cdot 4$

$16 \cdot 1$

16.5

15 pg

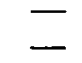

pg

pe

pg

pe

pe

pg

pe

pe

pg

pg

pe

pe

pe

pg

pe

pe

pg

pe

pe

pg

-

pe

pe

s.t.

Z. $A$ p. 34, I, 1954 (with Stock)

pe + pg pol. Astr. J. 58, 42, 1953

-

Ap. J. I17, 356, 1953

-

r.v.; s.t.

m.

p.m.

p.m.

-

s.t.

Ap. J. I19, I85, 1954

-

p.m.

-

p.m.

p.m.

s.t. $A p . J .119,622$, I 954

s.t.

pe $A p . J .117,469,1953$

pe $A p . J .117,313,1953$ 
Table 2a. Galactic Clusters (cont.)

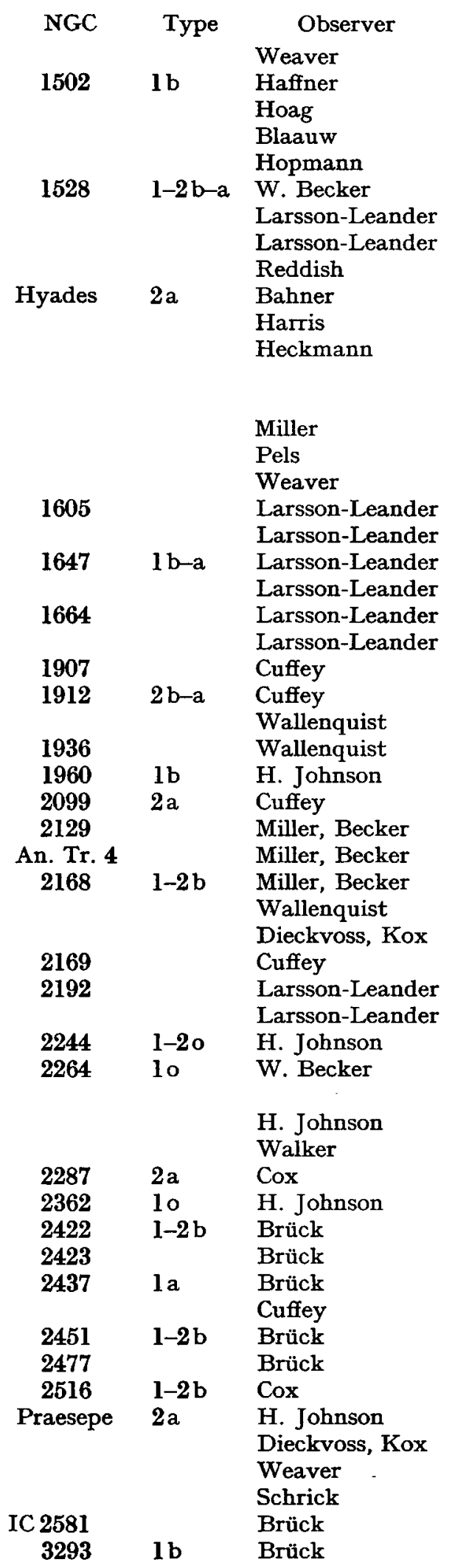

\begin{tabular}{|c|c|c|c|}
\hline $\bar{\lambda}$ & $\begin{array}{l}\text { Limiting } \\
\text { magnitude }\end{array}$ & Method & Data observed and reference \\
\hline- & $\ldots$ & - & s.t. \\
\hline 370427470645 & 12 & pg & pg pol. \\
\hline 430530 & 14 & pe & pg + pe pol. $A$ str. $J \cdot 5^{8}, 4^{2}, 1953$ \\
\hline 一 & - & - & p.m. \\
\hline- & - & - & p.m. \\
\hline 370470640 & $14 \cdot 5$ & $\mathrm{pg}$ & - \\
\hline 425530650 & 17 & pg & - \\
\hline 425530 & 15 & pe & s.t. \\
\hline 440640 & 15 & pg & - \\
\hline 430550 & $10 \cdot 7$ & pe & $\longrightarrow$ \\
\hline 370436553 & 14 & pe & - \\
\hline 427588 & $12 \cdot 5$ & Pg & $\begin{array}{l}\text { p.m. Mitt. A.G. 20, I952; Vistas } \\
\text { in Astronomy, in the Press; } \\
\text { Osvalds, } A . N .281,193,1954\end{array}$ \\
\hline 430640 & 18 & pg & - \\
\hline- & 12 & - & p.m. \\
\hline - & 一 & - & s.t. \\
\hline 425530650 & 17 & $\mathrm{pg}$ & s.t. \\
\hline 425530 & 15 & pe & - \\
\hline 425530650 & 17 & $\mathrm{pg}$ & 一 \\
\hline 425530 & 15 & pe & - \\
\hline 425530650 & 17 & $\mathrm{pg}$ & - \\
\hline 425530 & 15 & pe & - \\
\hline 430550 & 14 & pe & - \\
\hline 430550 & 14 & pe & - \\
\hline 419536 & $11 \cdot 5$ & pe & 一 \\
\hline 419536 & $11 \cdot 5$ & pe & - \\
\hline 370435550 & 15 & pe & $A p . J .117,3 \times 3,1953$ \\
\hline 430550 & 14 & pe & - \\
\hline 370470640 & 13 & pg & - \\
\hline 370470640 & 13 & pg & 一 \\
\hline 370470640 & 13 & pg & 一 \\
\hline 419536 & $11 \cdot 5$ & pe & - \\
\hline- & - & - & p.m. \\
\hline 430550 & 14 & pe & - \\
\hline 425530650 & 17 & pg & - \\
\hline 425530 & 15 & pe & - \\
\hline 370435550 & 15 & pe & - \\
\hline 370470585 & $11 \cdot 5$ & pe & $\begin{array}{l}\text { Z. Ap. 34, 31, 1954 (with } \\
\text { Stock) }\end{array}$ \\
\hline 370435550 & 15 & pe & - \\
\hline 370435550 & $16 \cdot 5$ & $p e+p g$ & s.t. \\
\hline 427534 & 13 & pe & $A p \cdot J .119,188,1954$ \\
\hline 370435550 & 15 & pe & $A p \cdot J .117,313,1954$ \\
\hline 350430630 & $15 \cdot 5$ & $\mathrm{pg}$ & - \\
\hline 350430630 & $15 \cdot 5$ & $\mathrm{pg}$ & - \\
\hline 350430630 & $15 \cdot 5$ & $\mathrm{Pg}$ & - \\
\hline 430550 & 14 & pe & 一 \\
\hline 350430630 & $15 \cdot 5$ & $\mathrm{pg}$ & - \\
\hline 350430630 & $15 \cdot 5$ & $\mathrm{pg}$ & - \\
\hline 427534 & 13 & pe & - \\
\hline 370435550 & 15 & pe & Ap. J. 116, 640, 1952 \\
\hline - & - & - & p.m. \\
\hline - & - & - & s.t. \\
\hline- & 13 & - & p.m. Veröff. Bonn, no. 40, 1954. \\
\hline 350430630 & $15 \cdot 5$ & $\mathrm{pg}$ & - \\
\hline 350430630 & $15 \cdot 5$ & $\mathrm{pg}$ & - \\
\hline
\end{tabular}


Table 2a. Galactic Clusters (cont.)

\begin{tabular}{|c|c|c|c|c|c|c|}
\hline NGC & Type & Observer & $\bar{\lambda}$ & $\begin{array}{l}\text { Limiting } \\
\text { magnitude }\end{array}$ & Method & Data observed and reference \\
\hline \multirow[t]{2}{*}{3532} & $2 \mathrm{~b}-\mathrm{a}$ & Houck & - & $\longrightarrow$ & - & 一 \\
\hline & & Koelbloed & 430550 & - & $\mathrm{pg}+\mathrm{pe}$ & +p.m. \\
\hline \multirow[t]{2}{*}{3766} & $1 \mathrm{~b}$ & Brück & 350430630 & $15 \cdot 5$ & $\mathrm{pg}$ & 一 \\
\hline & & Koelbloed & - & - & - & p.m. \\
\hline \multirow[t]{6}{*}{ Coma } & $2 \mathbf{a}$ & Bahner, Miczaika & 430550 & - & pe & Z. Ap. 31, 236, 1952 \\
\hline & & Thiessen & 410530 & 一 & pe & - \\
\hline & & Westerlund & 435550625 & $11 \cdot 5$ & $\mathrm{pg}$ & s.t. $A n n$. Uppsala, 3, no. 1o, 1953 \\
\hline & & Weaver & 430550 & 11 & pe & $A p \cdot J .116,612,1952$ \\
\hline & & Dieckvoss, Kox & - & - & - & p.m. \\
\hline & & Fehrenbach & - & - & - & r.v. \\
\hline $\begin{array}{l}4755 \\
5281\end{array}$ & $1-2 b$ & Koelbloed & - & - & 一 & p.m. \\
\hline $\left.\begin{array}{l}5316 \\
5999 \\
6005\end{array}\right\}$ & $1-2 b-a$ & Brück & 350430630 & $15 \cdot 5$ & pg & 一 \\
\hline 6124 & $2 b-a$ & Koelbloed & 430550 & - & $\mathrm{pg}+\mathrm{pe}$ & p.m. \\
\hline 6231 & 10 & Houck, Cox & 427534 & 一 & pe & $A p \cdot J .118,165,1953$ \\
\hline 6281 & & Koelbloed & - & - & - & p.m. \\
\hline 6405 & $1-2 b$ & Koelbloed & - & 一 & 一 & p.m. \\
\hline IC 4665 & $1-2 b$ & $\begin{array}{l}\text { H. Johnson } \\
\text { Weaver }\end{array}$ & $\begin{array}{c}370435550 \\
-\end{array}$ & 15 & $\underline{\mathrm{pe}}$ & $\begin{array}{l}A p \cdot J \cdot \text { I19, I } 81,1954 \\
\text { s.t. }\end{array}$ \\
\hline 6469 & & Svolopoulos & 430550 & 13 & $\mathrm{pg}$ & $\begin{array}{l}\text { Mon. Not. R. Astr. Soc. Ir3, 758, } \\
\mathbf{1 9 5 3}\end{array}$ \\
\hline 6475 & $1 \mathrm{~b}$ & Koelbloed & 430550 & 一 & $p g+p e$ & - \\
\hline 6494 & $2 \mathrm{a}$ & Svolopoulos & 430550 & 14 & pg & $\begin{array}{l}\text { Mon. Not. R. Astr. Soc. 113, } 75^{8} \text {, } \\
\text { I } 953\end{array}$ \\
\hline 6523 & & H. Johnson & 370435550 & 15 & pe & - \\
\hline 6531 & $1 \mathrm{~b}$ & H. Johnson & 370435550 & 15 & pe & - \\
\hline & & Svolopoulos & 430550 & 13 & pg & $\begin{array}{l}\text { Mon. Not. R. Astr. Soc. I13, } 75^{8} \text {, } \\
1953\end{array}$ \\
\hline 6546 & & Svolopoulos & 430550 & 13 & $\mathrm{pg}$ & $\begin{array}{l}\text { Mon. Not. R. Astr. Soc. Ir3, 758, } \\
\mathbf{1} 953\end{array}$ \\
\hline 6649 & & Cuffey & 430550 & 14 & pe & 一 \\
\hline 6705 & $2 b-a$ & H. Johnson & 370435550 & 15 & pe & - \\
\hline & & Meurers & - & 14 & - & p.m. Veröff. Bonn, no. 4 I, r954. \\
\hline 6802 & & Larsson-Leander & 425530650 & 17 & pg & - \\
\hline & & Larsson-Leander & 425530 & 15 & pe & s.t. \\
\hline 6811 & $2 a-f$ & W. Becker & 370470640 & $14 \cdot 5$ & $\mathrm{pg}$ & Z. Ap. 34, I, I954 (with Stock) \\
\hline 6823 & & W. Becker & 370470640 & $14 \cdot 5$ & pg & Z. Ap. 34, r, I954 (with Stock) \\
\hline 6866 & $\mathbf{2 a}$ & Dieckvoss, Kox & - & - & - & p.m. \\
\hline 6910 & & W. Becker & 370470640 & $14 \cdot 5$ & $\mathrm{pg}$ & Z. Ap. 34, I, I954 (with Stock) \\
\hline 6913 & $1 \mathrm{~b}$ & W. Becker & 370470640 & $14 \cdot 5$ & pg & $Z . A p .34, \mathrm{I}, \mathrm{I} 954$ (with Stock) \\
\hline & & Harris & 370436553 & $15 \cdot 5^{i}$ & pe & 一 \\
\hline 6939 & $\mathbf{3 a}$ & Cuffey & 430550 & 14 & pe & 一 \\
\hline 6940 & $2 \mathbf{a}$ & Larsson-Leander & $\begin{array}{l}425530650 \\
425530\end{array}$ & $\begin{array}{l}17 \\
15\end{array}$ & pg & s.t. \\
\hline 7092 & $1 \mathbf{a}$ & W. Becker & 370470640 & $14 \cdot 5$ & $\mathrm{pg}$ & $Z . A p .34, \mathrm{I}, \mathrm{1} 954$ (with Stock) \\
\hline & & Haffner & 370427640 & 14 & $\mathrm{pg}$ & - \\
\hline & & H. Johnson & 370436550 & 15 & pe & 一 \\
\hline & & Weaver & $\mathbf{4 3 0} 550$ & 11 & pe & $A p . J . \times 17,366, \mathbf{1 9 5 3}$ \\
\hline 7127 & & Svolopoulos & 430550 & 14 & $\mathrm{pg}$ & $\begin{array}{l}\text { Mon. Not. R. Astr. Soc. } 113,75^{8} \text {, } \\
\text { I953 }\end{array}$ \\
\hline 7128 & & Svolopoulos & 430550 & 14 & $\mathrm{pg}$ & $\begin{array}{l}\text { Mon. Not. R. Astr. Soc. I13, } 75^{8} \text {, } \\
\text { I953 }\end{array}$ \\
\hline 7209 & $1-2 a$ & W. Becker & 370470640 & $14 \cdot 5$ & $\mathrm{pg}$ & Z. Ap. 34, I, I954 (with Stock) \\
\hline IC 1434 & & Larsson-Leander & $\begin{array}{l}425530650 \\
425530\end{array}$ & $\begin{array}{l}17 \\
15\end{array}$ & $\begin{array}{l}\mathrm{pg} \\
\mathrm{pe}\end{array}$ & s.t. \\
\hline
\end{tabular}


Table 2a. Galactic Clusters (cont.)

\begin{tabular}{|c|c|c|c|c|c|c|}
\hline NGC & Type & Observer & $\bar{\lambda}$ & $\begin{array}{l}\text { Limiting } \\
\text { magnitude }\end{array}$ & Method & Data observed and reference \\
\hline 7243 & $1 \mathrm{~b}$ & W. Becker & 370470640 & $14 \cdot 5$ & pg & Z. Ap. 34, I, I954 (with Stock) \\
\hline 7380 & $1 \mathrm{~b}$ & Hoag & 430550 & 14 & $\mathrm{pe}$ & pg + pe pol. Astr. J. 58, 42, 1953 \\
\hline 7510 & & Miller, Becker & 370470640 & 14 & pg & - \\
\hline 7654 & $1 \mathrm{~b}-\mathrm{a}$ & Elvius & 430540 & 14 & $\mathrm{pg}$ & - \\
\hline
\end{tabular}

Table $2 b$. Observers and Instruments

\begin{tabular}{|c|c|c|c|}
\hline Name & Instrument & Locality & Data observed \\
\hline Bahner & 12 in. refr. & Heidelberg & - \\
\hline \multirow[t]{3}{*}{ W. Becker } & 24 in. Schmidt & Michigan & - \\
\hline & 24 in. refl. & Bergedorf & - \\
\hline & 48 in. refl. & Asiago & - \\
\hline Blaauw & 30 in. refr. & Allegheny & proper motions \\
\hline Brück & 36 in. ADH-tel. & Bloemfontein & - \\
\hline Cox & $\begin{array}{l}24 \text { in. Victoria tel. } \\
82 \text { in. refl. }\end{array}$ & $\begin{array}{l}\text { Cape } \\
\text { McDonald }\end{array}$ & $\begin{array}{l}\text { mag. } \\
\text { spectral types }\end{array}$ \\
\hline Cuffey & 40 in. refl. & Goethe Link Observatory & - \\
\hline Dieckvoss, Kox & $\begin{array}{l}24 \text { in. refr. } \\
4 \% 4 \text { astrograph }\end{array}$ & Bergedorf & - \\
\hline Eggen & 12 in. refl. & $\begin{array}{l}\text { Lick } \\
\text { Ling }\end{array}$ & - \\
\hline Elvius & 16 in. astrogr. & Stockholm & _- \\
\hline Fehrenbach & - & St Michel & - \\
\hline \multirow[t]{3}{*}{ Haffner } & 14 in Schmidt. & Göttingen & - \\
\hline & 14 in. astrograph & Göttingen & - \\
\hline & 32 in. Schmidt & Bergedorf & - \\
\hline Harris & 82 in. refl. & McDonald & - \\
\hline \multirow[t]{2}{*}{ Heckmann } & 14 in. Schmidt & Bergedorf & - \\
\hline & 12 in. astrograph & Bergedorf & - \\
\hline \multirow[t]{2}{*}{ Hoag } & 40 in. refl. & Washington & pe mag. + pe polarization \\
\hline & 26 in. refr. & Washington & pg polarization \\
\hline Hopmann & 14 in. refr. & Wjen/Castel Gandolfo & - \\
\hline \multirow[t]{2}{*}{ Houck } & - & Cape & - \\
\hline & - & Bloemfontein & - \\
\hline \multirow[t]{2}{*}{ H. Johnson } & 13 in. refl. & McDonald & - \\
\hline & 82 in. refl. & McDonald & - \\
\hline Koelbloed & 24 in. Victoria tel. & Cape & - \\
\hline \multirow[t]{3}{*}{ Larsson-Leander } & 40 in. refl. & Saltsjöbaden & spectra \\
\hline & 24 in. refr. & Saltsjöbaden & pg + pe mag. \\
\hline & 20 in. refr. & Saltsjöbaden & $\mathrm{pv}+\mathrm{pr}$ \\
\hline Meurers & 12 in. refr. & Bonn & - \\
\hline Miczaika & 12 in. refr. & Heidelberg & - \\
\hline Miller & 24 in. Schmidt & Michigan & - \\
\hline Pels & 13 in. refr. & Leiden & - \\
\hline Ponsen & 18 in. refl. & Leiden & - \\
\hline \multirow[t]{2}{*}{ Reddish } & 24 in. refr. & London, Mill Hill & pg mag. \\
\hline & 18 in. refr. & London, Mill Hill & pr mag. \\
\hline Roman & 82 in. refl. & McDonald & - \\
\hline Schrick & 12 in. refr. & Bonn & - \\
\hline \multirow[t]{2}{*}{ Svolopoulos } & 7 in. astrogr. & Norman Lockyer & - \\
\hline & $5: 5$ astrogr. & Norman Lockyer & - \\
\hline Thiessen & 24 in. refr. & Bergedorf & - \\
\hline Trumpler & div. & Lick & - \\
\hline \multirow[t]{3}{*}{ Walker } & 100 in. refl. & Mt Wilson & pe mag., spectral types \\
\hline & 60 in. refl. & Mt Wilson & - \\
\hline & 20 in. refl. & Mt Palomar & - \\
\hline 35 & & 545 & $A U$ IX \\
\hline
\end{tabular}


Table $2 b$. Observers and Instruments (cont.)

\begin{tabular}{lllc}
$\quad$ Name & Instrument & \multicolumn{1}{c}{ Locality } & Data observed \\
Wallenquist & 16 in. refl. & Kvistaberg/Uppsala & - \\
Weaver & 12 in. refr. & Lick & - \\
& 36 in. refl. & Lick & - \\
Westerlund & 100 in. refl. & Mt Wilson & Spectral types \\
& 6 in. refr. & Uppsala & - \\
& 12 in. Schmidt & Uppsala & -
\end{tabular}

\section{Completeness}

Discussion of Table 2 a

With regard to the names of the observers (column 3) one has to consider that:

I. Trumpler's name does not appear. He announced in December 1952 that about Ioo galactic clusters, not communicated individually, had been observed from 9-I4 pg. mag. 'Preliminary reduction completed. Will be published when radial velocities and spectral class determinations are completed.'

2. The report received from the U.S.S.R. is given on Pp. $344 \mathrm{ff}$.

\section{Effective wave-length}

The data in column 4 are not in all cases exactly the authors' own data, remarks like 'pg, pv, B, V, P' were replaced by suitable wave-lengths. It is evident from column 4 that most astronomers have decided to measure stellar magnitudes in three wave-length ranges:

$$
360-450-630 \text { or } 360-450-550 \text {. }
$$

There are remarkable differences in the effective wave-lengths of the blue, yellow or red spectral range, caused only partly by the difference of sensitivity of multiplier and emulsion (cf. column 6, Method). A certain standardization of receivers and colour filters should be seriously considered.

\section{Present status}

Because of the wide diversity of answers regarding the present status of work, no details are communicated. It is suggested that observers be asked for particulars.

\section{Selection of objects}

Table $2 a$ comprises 84 galactic clusters (M 67, M 7I, and NGC 7789 have been placed in the list of globular clusters). This total of 84 has to be compared with the total number of known clusters, 33I according to Trumpler, 47I according to Collinder.

The Trumpler spectral type of clusters (LOB 420) accounts for 50 clusters out of the 84 . Most of the observations are devoted to the types I o, I-2o, 20, I b, I-2b and $2 \mathrm{~b}(27 \mathrm{Com}$ pared with $5 \mathrm{I}$ in the Trumpler list) and to the rare 'late' types $3 \mathrm{a}, 2 \mathrm{a}-\mathrm{f}, 2 \mathrm{f}$ which are all under observation(z). Comparatively few of the intermediate types between $\mathbf{I} \mathbf{b}-\mathbf{a}$ and 2-3a (Hyades and Praesepe type) appear (20,' including Hyades, Praesepe and Coma, compared with 45 in the Trumpler list).

The main cause for the difference between the number of known and of observed clusters is the southern declination of many objects. Considering only the roo clusters of Trumpler type, one finds that 40 clusters have $\delta<-I 5^{\circ}$, but only ${ }_{5}$ of these are contained in Table $2 a$. Comparing the Trumpler list with Table $2 a$ it is easy to pick out clusters of special interest accessible to northern or southern observatories and hitherto unobserved with modern photometric methods.

\section{Requests}

Blaauw suggests that observatories having old series of cluster plates should make lists available with data of observation, scale, and magnitude limit. They should state whether they $(a)$ are willing to repeat plates on request; $(b)$ are not willing to repeat 
plates. In case $(b)$ new plates could be taken by similar instruments at other observatories.

Dieckvoss and Kox need radial velocities in NGC п039.

Miczaika urgently desires proper motions and radial velocities of possible members of Ursa Major group to improve identification of membership.

Miss Roman wants to get improved proper motion and radial velocity data of Heinemann no. 209 (Ao) in NGC 752 in order to check membership.

Svolopoulos needs spectral types for the clusters he has measured photometrically.

\section{Motions}

\section{Special remarks}

Dieckvoss and Kox (Bergedorf) are determining absolute proper motions in NGC 869, 884, I039, 2I68, 2632, 6866, and Coma. Their material consists of plate pairs either of 24 in. refr. or of $4: 5 \mathrm{AG}$ astrograph; limits are between $\mathrm{I} 2$ and $\mathrm{I}_{4} \mathrm{~m}_{\mathrm{pg}}$.

Heard is observing radial velocities in the $\alpha$ Per cluster.

Heckmann, Dieckvoss and Kox, by comparison of AGKI, CdC, AGK2, and new photographic positions, determined proper motions in the Hyades $\left(4^{\mathrm{h}} 4^{\mathrm{m}}\right.$ to $4^{\mathrm{h}} 34^{\mathrm{m}}$; $12^{\circ}$ to $\left.23^{\circ} 5\right)$ in order to derive individual parallaxes and around $\alpha \operatorname{Per}\left(3^{\mathrm{h}} 6^{\mathrm{m}}\right.$ to $3^{\mathrm{h}} 3^{6^{\mathrm{m}}}$; $46^{\circ} 37^{\prime}$ to $\left.51^{\circ} 37^{\prime}\right)$ where they found new faint members of the $B$ star cluster. Results are to be published in I955.

Oosterhoff reports that Pels is deriving proper motions in a field around the Hyades $\left(3^{\mathrm{h}} \mathrm{o}^{\mathrm{m}}\right.$ to $5^{\mathrm{h}} 24^{\mathrm{m}} ; 0^{\circ}$ to $\left.32^{\circ}\right)$, and, together with Blaauw, around $\alpha \operatorname{Per}\left(3^{\mathrm{h}} \mathrm{O}^{\mathrm{m}}\right.$ to $3^{\mathrm{h}} 5^{6^{\mathrm{m}}}$; $44^{\circ}$ to $\left.52^{\circ}\right)$. His method is comparison of astrographic catalogue positions with plates of Leiden $\mathrm{I}_{3}$ in. refr.

Osvalds (3) (Charlottesville, formerly Bergedorf) has derived proper motions in a $5^{\circ} \times 5^{\circ}$ field around $\theta^{2}$ Tauri. His material is 3 pairs of old and new AG plates; $\Delta$ epoch Io-20 years. He has found some new faint Hyades.

Stoy reports that Koelbloed, besides his photometric work, is deriving proper motions with Cape plates of NGC $3532,3766,4755 ; \Delta$ epoch I6 years.

Walker highly desires accurate proper motions in the area of NGC 2264, down to I9.5 $m_{\text {vis }}$.

\section{Spectral types}

Gratton together with Hernandez (La Plata) has determined spectral types and radial velocities of the brighter stars in the cluster near $\kappa$ Crucis.

Miss Roman in NGC 752 has observed spectral types in MK system, II $3 \AA / \mathrm{mm}$. at $\mathrm{H} \gamma$, limit $12.6 m_{\text {vis }}$, with the 82 in. McDonald. She also measured radial velocities on the same plates (material still incomplete). Her purpose is to obtain a H-R diagram, and luminosity standards for $\mathrm{F}$ subgiants.

Weaver has determined spectral types in Pleiades, Praesepe, Hyades, IC 4665, using the $36 \mathrm{in}$. Lick, and the Ioo in. Mt Wilson; dispersion, 75 and $37 \AA / \mathrm{mm}$., for a few Hyades Io and $2.9 \AA / \mathrm{mm}$. His purpose is to obtain spectral characteristics of clusters.

\section{Miscellaneous}

Miller (Michigan) has completed his observations for W. Becker. His Hyades programme consists of $20 \mathrm{~min}$. exposures ro3a-O without filter and $30 \mathrm{~min}$. ro3a-E with Wratten 22 (red). Luyten wants these plates for a search of abnormally blue and abnormally red stars.

Reddish has identified NGC 7789 as a population II object. It should therefore be rather classified as 'globular'.

Walker reports that he did not find in NGC 457 the abnormal Balmer discontinuity announced by W. Becker. 


\section{Globular Clusters}

\section{Table $3 a$. Globular Clusters}


Table 3a. Globular Clusters (cont.)

\begin{tabular}{|c|c|c|c|c|c|}
\hline NGC & Name & Observer & $\begin{array}{l}\text { Limiting } \\
\text { magnitude }\end{array}$ & Purpose & Reference \\
\hline 6401 & - & Sawyer Hogg & - & Var. & - \\
\hline \multirow{2}{*}{6402} & M 14 & Sawyer Hogg & - & Var. & - \\
\hline & & Arp & 17 & Var., $\mathrm{C}-\mathrm{m}$ & $-\overline{0}$ \\
\hline 6535 & - & Sawyer Hogg & - & Var. & Comm. David Dunlap, no. 34,1953 \\
\hline 6539 & - & Sawyer Hogg & - & Var. & - \\
\hline 6541 & - & Wilkens & - & Var. & - \\
\hline 6544 & 一 & Sawyer Hogg & - & Var. & - \\
\hline 6558 & - & Rosino & $18,20^{a}$ & Var., $\phi(M)$ & Contr. A siago, no. 52, I954 \\
\hline IC 1276 & - & Sawyer Hogg & 一 & Var. & - \\
\hline 6626 & - & Sawyer Hogg & - & Var. & - \\
\hline 6637 & M 69 & Rosino & $18,20^{a}$ & Var., $\phi(M)$ & 一 \\
\hline 6638 & - & Sawyer Hogg & - & Var. & - \\
\hline 6642 & -- & Sawyer Hogg & - & Var. & - \\
\hline \multirow[t]{2}{*}{6656} & - & Sawyer Hogg & - & Var. & - \\
\hline & & Wilkens & - & Var. & - \\
\hline \multirow[t]{2}{*}{6712} & - & Rosino & $18,20^{a}$ & Var., $\phi(M)$ & $\overline{-}$ \\
\hline & & Sawyer Hogg & - & Var. & Comm. David Dunlap, no. 34,1953 \\
\hline 6715 & M 54 & Rosino & $18,20^{a}$ & Var., $\phi(M)$ & Publ. Bologna, v, no. 18,1952 \\
\hline 6717 & - & Sawyer Hogg & - & Var. & - \\
\hline 6752 & - & Wilkens & - & Var. & - \\
\hline 6760 & - & Sawyer Hogg & - & Var. & Comm. David Dunlap, no. 34, I953 \\
\hline \multirow[t]{2}{*}{6779} & M 56 & Sawyer Hogg & - & Var. & Comm. David Dunlap, no. 34,1953 \\
\hline & & Rosino & $18,20^{a}$ & Var., $\phi(M)$ & - \\
\hline 6809 & M 55 & H. Johnson & 15 & $\mathrm{C}-\mathrm{m}$ & - \\
\hline \multirow[t]{4}{*}{6838} & M 71 & W. Becker & $17 \cdot 5$ & $\mathrm{C}-\mathrm{m}$ & - \\
\hline & & Cuffey & 18 & $\mathrm{C}-\mathrm{m}$ & - \\
\hline & & Rosino & $18,20^{a}$ & Var., $\phi(M)$ & Contr. A siago, no. 52, 1954 \\
\hline & & Sawyer Hogg & - & Var. & Comm. David Dunlap, no. 34,1953 \\
\hline 6864 & - & Rosino & $18,20^{a}$ & Var., $\phi(M)$ & - \\
\hline 6934 & - & Sawyer Hogg & - & Var. & $-1-$ \\
\hline \multirow[t]{2}{*}{6981} & M 72 & Rosino & $18,20^{a}$ & Var., $\phi(\mathbf{M})$ & Publ. Bologna, vi, no. 2, 1953 \\
\hline & & Sawyer Hogg & - & Var. & Comm. David Dunlap, no. 34, I953 \\
\hline 7006 & - & Rosino & $18,20^{a}$ & Var., $\phi(M)$ & - \\
\hline \multirow[t]{4}{*}{7078} & M 15 & Arp & 17 & $\mathrm{C}-\mathrm{m}, \phi(\mathrm{M})$ & - \\
\hline & & Baum & 23 & $\mathrm{C}-\mathrm{m}$ & - \\
\hline & & Hoag & - & Distribution of intensity & - \\
\hline & & Rosino & $18,20^{a}$ & Var., $\phi(M)$ & - \\
\hline \multirow[t]{2}{*}{7089} & M 2 & Arp & 17 & $\mathrm{c}-\mathrm{m}$ & - \\
\hline & & Hoag & - & Distribution of intensity & - \\
\hline 7099 & - & Rosino & $18,20^{a}$ & Var., $\phi(M)$ & - \\
\hline \multirow[t]{2}{*}{7492} & - & Cuffey & 18 & C-m & - \\
\hline & & Rosino & $18,20^{a}$ & Var., $\phi(M)$ & - \\
\hline 7789 & - & Reddish & 15 & $\mathrm{C}-\mathrm{m}$ & - \\
\hline
\end{tabular}


Table $3 b$. Observers and Instruments

\begin{tabular}{|c|c|c|c|c|}
\hline Name & Instrument & Locality & Effective wave-length & Method \\
\hline Arp & 200 in. refl. & Mt Palomar & 430540 & $\mathrm{pg}$ \\
\hline Baum & 200 in. refl. & Mt Palomar & 360430540 & \\
\hline \multirow[t]{2}{*}{ W. Becker } & See Table $2 b$ & & M $67: 370470640$ & pg \\
\hline & & & M 71: $\quad 430600$ & pg \\
\hline Cuffey & 36 in. refl. & Bloomington & 430630 & $\mathrm{pg}$ \\
\hline Eggen & 36 in. refl. & Lick & 430540 & pe \\
\hline Hoag & 40 in. refl. & Washington & 430530 & pe \\
\hline H. Johnson & 82 in. refl. & McDonald & 370435550 & pe \\
\hline Mayall & 36 in. refl. & Lick & 430540 & pe \\
\hline Oosterhoff & 74 in. refl. & Radcliffe & 430 & $\mathrm{pg}$ \\
\hline \multirow[t]{2}{*}{ Gaposchkin } & 60 in. refl. & & & \\
\hline & $\begin{array}{l}36 \text { in. ADH telescope } \\
10 \text { in. Metcaif }\end{array}$ & Bloemfontein & 430630 & $\mathrm{pg}$ \\
\hline Reddish & 24 in. refr. & London, Mill Hill & 440640 & pg \\
\hline \multirow[t]{2}{*}{ Rosino } & 24 in. refl. & Lojano (limit 18 mag.) & $\mathbf{4 3 0}$ & $\mathrm{pg}$ \\
\hline & 48 in. refl. & Asiago (limit 20 mag.) & 430 & $\mathrm{pg}$ \\
\hline \multirow[t]{2}{*}{ Sandage } & 200 in. refl. & Mt Palomar & 430540 & $\mathrm{pg}+\mathrm{F}$ \\
\hline & 100 in. ref. & Mt Wilson & 370430550 & pg \\
\hline \multirow[t]{2}{*}{ Sawyer Hogg } & 74 in. refl. & David Dunlap & 430 & $\mathrm{pg}$ \\
\hline & 19 in. refl. & David Dunlap & 430 & $\mathrm{pg}$ \\
\hline \multirow[t]{2}{*}{ Walker } & 100 in. refl. & Mt Wilson & 370435550 & pe \\
\hline & 60 in. refl. & Mt Wilson & 370435550 & pe \\
\hline Wilkens & 14 in. refr. & La Plata & 430 & pg \\
\hline van Woerden & 74 in. refl. & Radcliffe & 430 & $\mathrm{pg}$ \\
\hline
\end{tabular}

\section{Discussion of Table $3 a$}

The data on globular clusters have been arranged in Table $3 a$ in a similar manner to those on galactic clusters in Table $2 a$. They need little explanation. The effective wavelengths are given in Table $3 b$, together with the instruments used. On account of the nature of globular clusters there is a greater diversity in the purposes of the authors than in the case of galactic clusters. Therefore the purposes are given individually in column 5 (Remarks).

\section{Selection of clusters}

The total number of known globular clusters belonging to the Galactic System is rog, Mrs Sawyer Hogg's last Catalogue being enlarged by ten recent additions (NGC 2158, 2682 (M 67), 6235, 6535, 6558, 6642, 67I7, 7789, IC 1276 and Anon. I5 ${ }^{\text {b }}{ }^{1} 3^{\mathrm{m}}+0^{\circ} \mathrm{x}$ ) among which there may still be some dubious cases. Fifty-nine out of these are under observation. The distribution in declination of the known $\left(\mathrm{N}_{\text {tot }}\right)$ and the observed $\left(\mathrm{N}_{0}\right)$ clusters may be seen from Table 4 .

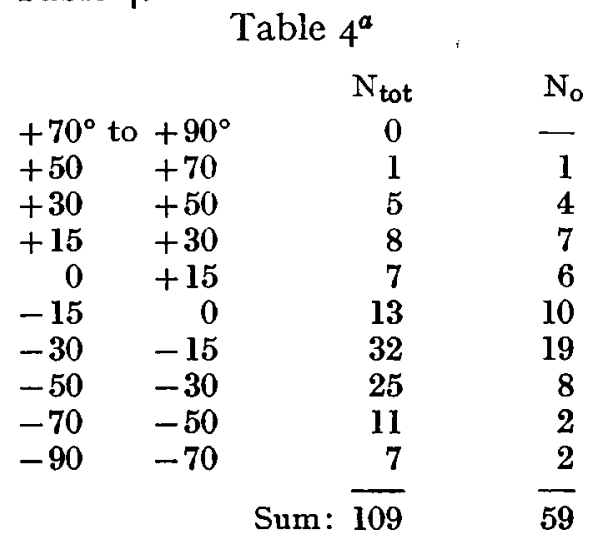

a In most of the southern globular clusters now under observation only variables are investigated. 


\section{Requests}

Baum reports that the main series in $M_{3}$ and probably in $M_{3}$ and $M_{5}$ may be in the sub-dwarf region. He therefore suggests a more intensive study of sub-dwarfs in the general field, particularly towards determining their location and spread in the CMD.

Rosino recommends that observations of variable stars in clusters be made by observers working at different geographic longitudes.

Mrs Sawyer Hogg asks for radial velocities of bright variables in globular clusters in order to decide their membership.

Walker needs spectroscopic observations of red stars in NGC 4 I47 because of the photometrically established abnormally strong ultra-violet. Comparison with $\mathbf{M}_{3}$, where H. L. Johnson found the same phenomenon, is suggested.

\section{Miscellaneous remarks}

Gratton, besides the data given in Table $3 a$, reports on investigations by $H$. Wilkens on diameters of globular clusters determined by the distribution of known variables.

Mrs Sawyer Hogg is preparing a second edition of the catalogue of variables in globular clusters, comprising I42I entries. The catalogue will be published before the Dublin meeting of the I.A.U. In $\mathrm{M}_{3}$ and $\mathrm{M} 92$ Walker is investigating photo-electrically stars at either edge of the variable star gap for incipient variability.

\section{Globular clusters in extragalactic objects}

Kron and Mayall are determining pe magnitude of 60 globular clusters in $\mathrm{M}$ 3I for comparison of absolute magnitude in the galaxy. They want to study absorption in M 3I, and intend to use globular clusters as distance indicators for nebulae in Virgo cluster having identified globular clusters.

Shapley (4) reports on photometry of 'Constellations' in the Large Magellanic Cloud and on the cataloguing and description of open and globular clusters in the Large and Small Magellanic Clouds; the instruments used were the Boyden Station ADH and 60 in. He hopes to complete this work in I955 or 1956.

\section{Work on Associations, Galactic Clusters, and Globular Clusters IN THE U.S.S.R.}

\section{Stellar associations}

B.E. Markarian (5) published a revised list of O-type stellar associations containing data about nineteen reliable and six probable associations.

V. A. Ambartsumian (6) found a close connexion between irregular and semi-regular supergiants of late spectral classes and the $\mathrm{O}$-associations. This may prove that these M-type supergiants are stars of a comparatively recent origin.

A number of papers were devoted to individual O-associations. B. E. Markarian (7) showed that the system of bright stars of early spectral classes in the Cep II association is expanding.

N. M. Artiukhina (8) derived proper motions of stars of the same association and confirmed the expansion found by B. E. Markarian.

I. M. Kopylov (9) investigated the association around the open cluster NGC 623I in Scorpius. In the same papers he studied the instability of associations in Scorpius, CepII, PerII and the Scorpio-Centaurus stream, and showed that the total energies of all these systems are positive.

P. P. Parenago (10) completed his investigation of the stellar system associated with the Orion nebula. In a region of 9 square degrees, with the nebula in its centre, magnitudes and colour indices of 3000 stars with magnitudes up to 14.5 , the equatorial co-ordinates of 2200 stars, and the proper motions of I500 stars were determined (the 
latter by N. M. Artiukhina, in the majority of cases). In the same region 224 variable stars of RW Aurigae type were studied.

The colour magnitude diagram was found to be rather peculiar. It consists of the first part of the Main Sequence, extending from O-type stars to A 5-type stars, only, and of a group of subgiants. Variable stars of RW Aurigae type are distributed in the same regions of the diagram.

Systematic motions of stars in different parts of the system were studied. The motions of the Trapezium stars confirm its expansion. The distribution in space of all the B stars belonging to the Orion association was also studied. P. P. Parenago concludes that this association is of a comparatively recent origin.

T. A. Uranova (II) completed a photographic study of the stellar system connected with the nebula NGC 2264 in the region of S Mon.

In a theoretical study, devoted to an interpretation of the observed peculiarities in the motion of stars of spectral classes $\mathrm{O}$ and $\mathrm{B}, \mathrm{A}$. F. Torondzhadze (12) showed that the system of bright stars in the neighbourhood of the Sun can be considered as a result of the expansion and disintegration (dissipation) of stellar associations, of a comparatively recent origin.

\section{Open clusters}

An Atlas of Open Star Clusters of Different Types by B. E. Markarian was published in 1952. It contains photographs of thirty-seven clusters of all types according to the author's classification, obtained at the. Byurakan Astrophysical Observatory by means of a I2-8 inch Schmidt camera.

The colour magnitude diagram was photographically determined by means of the r5-inch Schmidt camera of the Engelhardt Observatory for the clusters NGC I88, I528, I545, 68II, 6823, 6830, 6996, 7086 and Col. 428 by K. A. Barkhatova and for the clusters NGC I5I3, I664 and 7039 by L. J. Melnikova.

Second-epoch plates of the open star clusters NGC I29, 457, 58I, 752, 869, 884, I5I3, I907, I9I2, I960, 2099, 2168, 6705, 6885, 7092, and 7209 were taken with the normal astrograph of the Pulkovo Observatory.

V. V. Lavdovsky obtained the relative proper motions of the stars of twelve of these clusters and their surroundings (on the average about rooo stars in each cluster), from three to five pairs of plates. The probable error of the proper motion of an individual star is \pm 0 " oor for the mean of four pairs of plates. Photographic magnitudes of all the stars up to $\mathrm{I} 4-\mathrm{I}^{\mathrm{m}}$ were determined for five clusters with a precision of $\pm \mathrm{o}^{\mathrm{m}} \cdot 2$. V. V. Lavdovsky (r3) also published a paper on the determination of the magnitude equation in the proper motions of stars in NGC 6885 .

P. A. Savizky investigated the proper motions of 820 stars in the region of NGC 7654 (14) and of $43 \mathrm{I}$ stars in the region of NGC 6885 (15).

N. M. Artiukhina ( 16 ) investigated the proper motions of IIoo stars up to the $15^{\text {th }}$ magnitude in the region of the North Pole of the Galaxy in the field of Coma Berenices. A comparison of the luminosity functions of the Pleiades, Hyades, Praesepe and Coma Berenices was carried out. N. M. Artiukhina is also determining the proper motions of the cluster $\mathrm{H} 20$.

On the basis of a study of the motions of the bright stars in IC 2602 B. E. Markarian (r7) arrived at a conclusion about the expansion of this cluster (type $\mathrm{O}$ according to his classification). He suggests ( 18 ) that the majority of $\mathrm{O}$-type clusters does not transform into B- and A-type clusters, but are rapidly dissociating, because of the fact that their energy is positive. I. M. Kopylov, in his above-mentioned studies, arrived at similar conclusions.

N. N. Gorokhova (rg), by means of the Pulkovo mirror and lens camera with a directvision prism, completed the spectrophotometric investigation of thirty-two stars in the Coma Berenices cluster and of the eight brightest stars in the Pleiades. From spectrophotometric gradients and from other data she derived the absorption of light in the region of these clusters. She concluded that the Pleiades are the younger cluster. 
K. A. Barkhatova and V. V. Syrovoi (20) studied the average colour indices depending upon the distance from the centre in twenty-four open clusters, and found an increase of the average colour indices towards the periphery of the latter. Such an effect is interpreted by the authors as a consequence of the preferential distribution of stars of lower luminosity at the periphery of the clusters, as a result of their departure from the clusters.

K. A. Barkhatova (2x) showed that clusters with a large quantity of stars of various luminosities and with a weak concentration towards their centre, possess the largest galactic concentration.

I. M. Kopylov (22) determined the absolute integral magnitudes of 300 open clusters and obtained their luminosity function, which turned out to be close to the normal distribution with a maximum about $-3^{\mathrm{m} \cdot 5}$.

\title{
Globular clusters
}

Proper motions of the cluster M I3 were determined by N. V. Fatchikhin (23). N. M. Artiukhina is completing the determination of the proper motion of the cluster $\mathrm{M} 7 \mathrm{I}$. A series of studies by P. N. Kholopov (24), devoted to the investigation of the apparent and spatial distribution of different types of stars in a number of globular clusters, was published. It was discovered by the author that the globular clusters consist of a number of zones, each of them characterized by certain values of the average density gradient. The boundaries of these zones are rather distinct. Going from one zone to the next one, the gradient of the spatial density changes by one order of magnitude. The orientation of the ellipsoid of equal apparent density in the inner regions of some clusters differs from the corresponding orientation in the outer regions. Papers by I. N. Minin (25) on an application of the equations of stellar hydrodynamics to globular clusters, and by G. M. Idlis (26) on criteria of the tidal stability and the distribution of globular clusters in galaxies and of stars in globular clusters, are devoted to a theoretical analysis of the problems of the structure and development of globular clusters.

In conclusion, I wish to thank $\mathrm{H}$. Haffner for his continuous and effective help in preparing this report.

\author{
O. Heckmann \\ President of the Commission
}

\section{REFERENCES}

(I) W. W. Morgan et al., Ap. J. 118, 318, 1953.

(2) J. F. Cox, $A p$. J. 118, 165, 1953.

(3) V. V. Osvalds, $A . N$. 281, 193, 1954.

(4) H. Shapley, Havvard Rep. no. 372, 1953; no. 382, 1954.

(5) B. E. Markarian, C.R. Acad. Sci. R.S.S. Arménie, 15, no. 1, 1952.

(6) V. A. Ambartsumian, C.R. Acad. Sci. R.S.S. Arménie, 16, no. 3, 1953.

(7) B. E. Markarian, Comm. Byurakan Obs. no. II, 1953.

(8) N. M. Artiukhina, Astr. J. U.S.S.R. 3r, no. 3, 1954.

(9) I. M. Kopylov, Publ. Crim. Astrophys. Obs. II, 8I, 1954; C.R. Acad. Sci. U.R.S.S. 9o, no. $6,975,1953$.

(1о) P. P. Parenago, Astr. J. U.S.S.R. 30, no. 3, 1953; Publ. Sternberg State Astr. Inst. 25 , I954.

(I I) T. A. Uranova, Astr. Circ. U.S.S.R. I38, 1953.

(r2) A. F. Torondzhadze, Bull. Abastumani Obs. no. 15, 1953.

(13) V. V. Lavdovsky, Transactions of the Tenth Astrometrical Conference, Leningrad, r954.

(14) P. A. Savizky, Publ. Tashkent Astr. Obs. (II), 4, 1954.

(I5) P. A. Savizky, Publ. Tashkent Astr. Obs. (II), 3, 1953.

(16) N. M. Artiukhina, Astr. J. U.S.S.R. 30, no. 6, I953. 
(I7) B. E. Markarian, Comm. Byurakan Obs. no. II, 1953.

(18) B. E. Markarian, Comm. Byurakan Obs. no. I2, 1954.

(19) N. N. Gorokhova, Bull. Pulkovo Obs. no. 153, in the Press.

(20) K. A. Barkhatova and V. V. Syrovoi, Astr. J. U.S.S.R. 29, no. 6, I952.

(2 I) K. A. Barkhatova, Astr. J. U.S.S.R. 29, no. 6, 1952.

(22) I. M. Kopylov, Publ. Crim. Astr. Obs. 8, I22, 1952.

(23) N. V. Fatchikhin, Bull. Pulkovo Obs. 19, no. 148, 1952.

(24) P. N. Kholopov, Publ. Sternberg State Astr. Inst. 23, 250, 1953; Astr. J. U.S.S.R. 29, no. 6, I952, and 30, no. 4, no. 5, I953; Variable Stars, 9, no. 6, 1954.

(25) I. N. Minin, Trans. Leningrad Univ. no. 153, 60, 1952.

(26) G. M. Idlis, C.R. Acad. Sci. U.R.S.S. 9r, no. 6, 1953.

Report of the meeting. 30 August I955

President: Prof. O. Heckmann.

SeCretary: Dr J. Cuffey.

The participants stood during some words by the President in memory of $\mathrm{H}$. Mineur.

No comments were made on the published report.

After some general remarks, the Chairman suggested a discussion of the following points, which had already arisen in preparing the report.

(r) Blaauw's proposal (cf. p. 339) that lists of old cluster plates be published.

(2) Desirability of a uniform three-colour system to be applied to the photometry of star clusters.

(3) Extension of Trumpler's cluster classification to clusters of hitherto unknown Trumpler type.

(4) Desirability of MK spectral types in clusters.

(5) Discovery of new clusters.

(I) It is well known that a number of observatories possess old plates of star clusters which could be used with new exposures taken with the same instruments for the derivation of proper motions. Following a suggestion by A. Blaauw, these observatories are requested to prepare lists of such plate material in their files. It is further suggested that these lists be forwarded to the Chairman of Commission 37, who will collect and prepare them for publication. The lists should include the following necessary information regarding the plates:

(a) Instrument.

(b) Scale.

(c) Size of field.

(d) Object.

(e) I950 co-ordinates of the plate centre.

(f) Date of observation.

(g) Exposure time.

(h) Limiting magnitude.

(i) Quality.

It should further be stated whether the observatory will be able to repeat exposures on request and whether it will be able to undertake the reduction of the plates or would be willing to turn them over to other astronomers for reduction. It is hoped that this procedure will result in a systematic evaluation of the galactic and globular cluster material which has not as yet been fully evaluated.

F. Becker (Bonn) and J. Hopmann (Vienna) reported in detail on the plate material available at their institutions for the derivation of proper motions in clusters. H. F. Weaver (Mount Hamilton) called attention to a series of plates taken some time ago by R. F. Trumpler at the Allegheny Observatory.

(2) Since the last meeting of the I.A.U., astronomers have come to closer agreement with regard to the usefulness of magnitudes of cluster stars in at least three, rather than 
two, spectral ranges. According to the work of W. Becker and of H. L. Johnson threecolour photometry will yield distances and absorptions under the assumption that the relations between their intrinsic colours and absolute magnitudes are identical for different clusters. In order to facilitate the comparison of results of various investigators, the President suggests that all photometric work on clusters be done in the three-colour UBV system of Johnson and Morgan, if possible, since this is at present the most practical system. It was pointed out during the discussion that not only the effective wave-lengths but also wave-length ranges of the UBV system should be adopted. It was suggested that Commission 37 support the relevant resolutions of Commission 25 (Photometry).

(3) The selection of galactic clusters in most of the current investigations is based on Trumpler's type classifications ( $\mathrm{LOB} 420$ ), which characterize briefly the distribution of giant stars in the H-R diagram. However, these Trumpler types are known for only roo clusters. It is therefore highly desirable to inaugurate investigations which will determine Trumpler types for additional clusters. In view of the existing plate material, this would be possible for a number of galactic clusters without the necessity of taking new plates.

For the southern sky in any case, this problem has only been studied very incompletely.

Naturally, the Trumpler types are no substitute for a more extensive spectral classification.

(4) A more extensive and extremely desirable task, though it would naturally be laborious, would be the establishment of spectral types on the MK system. In combination with colour indices, this would yield not only the cluster-type, but also a knowledge of the distance of the cluster and the absorption in front of it. This method does not depend on the same assumptions as that discussed under point (2). MK types are not yet available for many of the Ioo clusters with known Trumpler types. This would require relatively high dispersion and therefore larger telescopes. Objective prism work will be possible only in certain cases. A. Underhill reports work of this nature in Victoria (with G. L. Odgers and R. M. Petrie). L. Gratton reports analogous work in Cordoba.

(5) The question of the discovery of new clusters leads to several useful points of view:

(a) The Franklin-Adams Charts have already been exhausted for this purpose by Collinder. The limiting magnitude in this case is I6.

(b) The limiting magnitude of 20 in the Palomar Sky Survey leads to such high star densities in the Milky Way, that clusters in which the brightest stars are of magnitude r6 or fainter could be found only under exceptional circumstances.

(c) A survey to a limiting magnitude of about $\mathbf{1} 8$ would be more desirable in many respects. It is probable that existing plate material could be used in part for this purpose.

(d) Even more important is the application of highly sensitive infra-red plates (for example, Eastman I-N), which would increase the probability of discovery of new clusters by virtue of being less affected by absorption.

The session ended with the forming of two resolutions:

Resolution $\mathrm{I}$ : Identical in content with point ( $\mathrm{I}$ ) above.

Resolution 2: Commission 37 supports resolutions I, 2 and 3 as approved by Commis$\operatorname{sion} 25$. 
Report of meeting. I September 1955

President: Prof. O. Heckmann.

Secretary: Dr J. Cuffey.

Agenda :

(I) Resolutions to approve.

(2) Additional reports (Weaver, Kholopov, Mrs Sawyer Hogg).

(3) Remarks on globular clusters.

(4) M. Schwarzschild: On the evolutionary tracks in the CM-diagram. Discussion.

(I) The Commission passed the two resolutions discussed at the first session.

(2) H. F. Weaver gave a short report on R. Trumpler's more recent work on galactic clusters. The extensive radial velocity observations are now complete. The publication is planned to include a catalogue of the radial velocity for each star (usually with three or more observations), magnitudes, colours, and a chart of each cluster with identification numbers on it. A discussion of the radial velocity material will be published later.

P. N. Kholopov read the following additions to the Draft Report:

T. S. Kirillova (Moscow) derived photographically (in photographic and red light) CMdiagrams for the open clusters NGC 2175, 2244, IC 1805, Tr. 37 and Col. 377.

N. M. Shakhovskoy in Moscow has completed his investigation of the Cep II association. He showed that a large number of $B$ and.A stars belong to that association.

N. M. Artiukhina (Moscow), as a continuation of her previous work, has derived and improved the proper motions of another forty B stars in the region of the Cep II association, which belong to that association according to Shakhovskoy. Proper motions of sixty $\mathrm{O}$ and $B$ stars in the above region suggest that the expansion of this association originates at two centres: cluster $\operatorname{Tr} 37$ and cluster NGC 7 I60.

In addition Mr Kholopov handed over to the Commission copies of a manuscript by A. I. Lebedinsky and O. B. Khorosheva entitled: 'On the Origin of the OB-type star associations'. This work will be published elsewhere.

(3) L. Rosino suggested that a survey for variable stars be made in all globular clusters north of $-20^{\circ}$ declination. There are thirty-four clusters in Mrs Sawyer Hogg's catalogue in which no search for variables has been made.

Mrs Sawyer Hogg presented to the Commission a copy of the second edition of her catalogue of variables in globular clusters.

(4) M. Schwarzschild, on request of the President, was kind enough to give a report on his work on the evolutionary interpretation of the CM-diagrams of clusters. He summarizęs his report as follows:

The Hertzsprung-Russell diagrams of Clusters as a Key Test of the Theory of Stellar Evolution

Before 1938 the theory of the stellar interior was badly handicapped by the fact that the nuclear processes which provide the energy sources within a star were unknown. In consequence, the equilibrium structure of a star of given mass and composition could not be derived uniquely, and comparison with observations was largely restricted to the mass-luminosity relation, which is fairly independent of the character of the nuclear processes.

Now that the necessary nuclear data are available, one can not only derive the initial structure of a star without arbitrariness, but one can even follow the star in its evolution, by computing at each evolution phase the changes in composition caused by the nuclear transmutations, and by constructing for each phase a new model of the star with due regard to the changed composition. From such model sequences one can then derive the luminosity and radius of the star as a function of time and thus obtain the evolutionary track of the star in the Hertzsprung-Russell diagram.

It appears likely that the stars of one cluster are essentially of the same age and initial composition. Accordingly, if we compute a family of evolutionary tracks for stars of the

$$
55^{6}
$$


same initial composition, but of different masses, and if we draw across these tracks in the Hertzsprung-Russell diagram the curves which connect points of equal age, then these curves should be identical with the observed Hertzsprung-Russell diagrams of clusters. It is for this reason that the Hertzsprung-Russell diagrams of clusters have recently gained the key role among the observational tests of the theory of stellar evolution.

The necessary theoretical work to compute evolutionary tracks is extensive. The use of large electronic machines is just now starting to speed up this work enormously. This far only the earliest evolution phases have been investigated in some detail. These investigations indicate that the well-known turn-off from the main-sequences of the brightest stars in each galactic cluster may be understood in terms of hydrogen depletion in the core of the stars. For globular clusters the analysis has been carried somewhat further, and it appears that the entire giant sequence in these clusters can be interpreted by the growth of hydrogen-exhausted, partially degenerate cores. The investigation of the latest evolutionary phases, which may well be represented by the horizontal branch in the globular clusters and by the yellow and red supergiants in galactic clusters, has hardly yet begun.

It is obvious that this theoretical development will be successful only if it will be guided phase by phase by the relevant observational data. The available data regarding the Hertzsprung-Russell diagrams of clusters have enormously increased in the last few years. Still, a good number of critical deficiencies are left. For example, the data on the supergiants in galactic clusters are still weak: very few clusters of intermediate age such as $M 6_{7}$ have as yet been thoroughly investigated; only for a very small sample have the delicate differences between various globular clusters been determined accurately. The solving of such observational problems appears fully as necessary as the parallel theoretical investigations if we are to gain speedily a fuller picture of stellar evolution.

The discussion touched the following points: Influence of rotation on mixing of stellar material; relation of the variable-star content in globular clusters to the form of the red branches in CM-diagrams; possibility of classifying clusters by means of their variables.

W. W. Morgan called attention to the two-colour diagram in which U-B is plotted versus $\mathrm{B}-\mathrm{V}$ as abscissa. This is available now for some galactic clusters. There is a tendency for Population II stars of type $\mathrm{F}_{2}$ to $\mathrm{Go}_{0}$ to lie somewhat (some $\mathrm{o}^{\mathrm{m}} \cdot \mathrm{or}$ ) above the stars of the Sun's neighbourhood. Accordingly the youngest clusters may lie lower and the oldest higher than those of intermediate age. For such diagrams photo-electric rather than photographic accuracy is required.

Schwarzschild emphasized that, irrespective of its theoretical interpretation, the two-colour diagram is important as a new means of sorting clusters in sub-groups. 